\title{
Is there an association between symptoms of anxiety and depression and quality of life in patients with chronic obstructive pulmonary disease?
}

\author{
Verônica F Parreira PhD ${ }^{1,2,3}$, Renata N Kirkwood PhD4, Megan Towns MScPT², Isabel Aganon MScPT ${ }^{2}$, Lauren Barrett MScPT², \\ Catherine Darling MScPT ${ }^{2}$, Michelle Lee MScPT ${ }^{2}$, Kylie Hill PhD²,5, , Roger S Goldstein PhD², Dina Brooks PhD ${ }^{2,3}$
}

\begin{abstract}
VF Parreira, RN Kirkwood, M Towns, et al. Is there an association between symptoms of anxiety and depression and quality of life in patients with chronic obstructive pulmonary disease? Can Respir J 2015;22(1):37-41.
\end{abstract}

BACKGROUND: In addition to symptoms, such as dyspnea and fatigue, patients with chronic obstructive pulmonary disease (COPD) also experience mood disturbances.

OBJECTIVE: To explore the relationships between health-related quality of life measures collected from patients with stable COPD and a commonly used measure of depression and anxiety.

METHODS: The present analysis was a retrospective study of patients with COPD enrolled in a pulmonary rehabilitation program. Hospital Anxiety and Depression Scale (HADS), Chronic Respiratory Disease Questionnaire (CRQ), Medical Research Council dyspnea scale and $6 \mathrm{~min}$ walk test data were collected. Statistical analyses were performed using Spearman's correlations, and categorical regression and categorical principal component analysis were interpreted using the biplot methodology. RESULTS: HADS anxiety scores retrieved from 80 patients were grouped as 'no anxiety' $(\mathrm{n}=43[54 \%])$, 'probable anxiety' $(\mathrm{n}=21$ [26\%]) and 'presence of anxiety' ( $\mathrm{n}=16[20 \%])$. HADS depression scores were similarly grouped. There was a moderate relationship between the anxiety subscale of the HADS and both the emotional function $(\mathrm{r}=-0.519 ; \mathrm{P}<0.01)$ and mastery $(\mathrm{r}=-0.553 ; \mathrm{P}<0.01)$ domains of the CRQ. Categorical regression showed that the CRQ-mastery domain explained $40 \%$ of the total variation in anxiety. A principal component analysis biplot showed that the highest distance between the groups was along the mastery domain, which separated patients without feelings of anxiety from those with anxiety. However, none of the CRQ domains were able to discriminate the three depression groups.

CONCLUSIONS: The CRQ-mastery domain may identify symptoms of anxiety in patients with COPD; however, the relationship is not strong enough to use the CRQ-mastery domain as a surrogate measure. None of the CRQ domains were able to discriminate the three depression groups (no depression, probable and presence); therefore, specific, validated tools to identify symptoms of depression should be used.

Key Words: Assessment; Chronic Respiratory Disease Questionnaire; Healthrelated quality of life measures; Hospital Anxiety and Depression Scale

\section{Y a-t-il un lien entre les symptômes d'anxiété et de dépression et la qualité de vie chez les patients atteints d'une maladie pulmonaire obstructive chronique?}

HISTORIQUE : En plus de symptômes comme la dyspnée et la fatigue, les patients ayant une maladie pulmonaire obstructive chronique (MPOC) ont également des troubles de l'humeur.

OBJECTIF : Explorer le lien entre la qualité de vie liée à la santé colligée auprès de patients atteints d'une MPOC stable et une mesure courante de dépression et d'anxiété.

MÉTHODOLOGIE : La présente étude rétrospective portait sur des patients atteints d'une MPOC participant à un programme de réadaptation pulmonaire. Les chercheurs ont colligé des données sur l'échelle HADS d'anxiété et de dépression à l'hôpital, le questionnaire CRQ de maladie respiratoire chronique, l'échelle de dyspnée du Conseil de recherche médicale et le test de marche de 6 minutes. Ils ont effectué les analyses statistiques à l'aide des corrélations de Spearman, d'une analyse de régression catégorielle et d'une analyse en composantes principales catégorielles interprétées par la méthodologie du biplot.

RÉSULTATS : Les scores d'anxiété HADS obtenus auprès de 80 patients étaient divisés entre " anxiété absente » $(\mathrm{n}=43$ [54 \%]), « anxiété probable » $(\mathrm{n}=21[26 \%])$ et « anxiété présente » $(\mathrm{n}=16[20 \%])$. Les scores de dépression HADS étaient divisés de manière similaire. Il y avait un lien modéré entre la sous-échelle HADS et les domaines de fonction émotionnelle ( $\mathrm{r}=-0,519$; $\mathrm{P}<0,01)$ et de maîtrise $(\mathrm{r}=-0,553 ; \mathrm{P}<0,01)$ du questionnaire CRQ. La régression catégorielle a révélé que le domaine de maîtrise du questionnaire CRQ expliquait $40 \%$ de la variation totale de l'anxiété. Un biplot d'analyse à composantes principales a révélé que la plus longue distance entre les groupes se situait dans le domaine de la maitrise, qui distinguait les patients sans sentiments d'anxiété de ceux en éprouvant. Cependant, aucun des domaines du questionnaire CRQ n'a pu discriminer les trois groupes de dépression.

CONCLUSIONS : Le domaine de maittrise du questionnaire CRQ pourrait révéler des symptômes d'anxiété chez les patients atteints de MPOC. Cependant, le lien n'est pas assez solide pour qu'il soit utilisé comme mesure substitutive. Aucun des domaines de ce questionnaire ne pouvait discriminer les trois groupes de dépression (dépression absente, probable et présente). Il faudrait donc utiliser des outils validés précis pour déterminer les symptômes de dépression.
Chronic obstructive pulmonary disease (COPD) is a common condition with a high impact on mortality, morbidity and health resource utilization $(1,2)$. Although the cardinal complaints of individuals with COPD are symptoms of dyspnea and fatigue $(3,4)$, many also experience secondary mood disturbances. The reported prevalence of feelings of anxiety and depression varies considerably, from 2\% to $96 \%$ for anxiety, and from $7 \%$ to $42 \%$ for depression. This disparity may be related to several factors such as sample size and heterogeneity of the populations, instruments used during assessment as well the threshold considered to identify the presence of these feelings $(5,6)$.

Depression and anxiety are associated with more frequent exacerbations in patients with $\operatorname{COPD}(7,8)$, worse short-term survival and higher rates of postexacerbation readmission to hospital (9). Moreover, Lou et al (10) recently reported an interaction effect between symptoms of depression and anxiety and death among patients with COPD. Therefore, it is important to reduce depression and anxiety; reductions in anxiety and depression are associated with pulmonary rehabilitation (PR) (11-15). Despite the potential for exercise to reduce depression and anxiety, most PR programs do not include a recommended assessment of mood disturbances (16), even among patients with severe and longstanding COPD in whom depression and anxiety are most likely to be present (17). The Hospital Anxiety and Depression Scale (HADS) is an instrument used to measure feelings of anxiety and depression (18); its measurement properties have been validated (19). The HADS has

${ }^{1}$ Department of Physical Therapy, Universidade Federal de Minas Gerais, Belo Horizonte, Brazil and Fellow (CAPES - Brazil); ${ }^{2}$ Department of Physical Therapy, University of Toronto, ${ }^{3}$ Department of Respiratory Medicine, West Park Healthcare Centre, Toronto, Ontario; ${ }^{4} \mathrm{Graduate}$ Program in Rehabilitation Sciences, Universidade Federal de Minas Gerais, Belo Horizonte, Brazil; ${ }^{5}$ School of Physiotherapy and Curtin Health Innovation Research Institute, Curtin University; ${ }^{6}$ Lung Institute of Western Australia and Centre for Asthma, Allergy and Respiratory

Research, University of Western Australia, Perth, Australia

Correspondence: Dr Dina Brooks, Department of Physical Therapy, University of Toronto, 160-500 University Avenue, Toronto, Ontario M5G 1V7.

Telephone 416-978-1739, fax 416-946-8562, e-mail dina.brooks@utoronto.ca 
been used in studies assessing patients with $\operatorname{COPD}(8,20,21)$. A minimally important difference of 1.5 has been established among patients with moderate to severe COPD (21).

PR programs routinely assess health-related quality of life (HRQoL) and exercise capacity. Among the different tools used in assessing HRQOL in patients with COPD, the self-administered Chronic Respiratory Disease Questionnaire (CRQ) is one of the most widely used in Canada (17). It is a disease-specific tool used to assess quality of life of patients with COPD $(13,14,21)$. Its reproducibility, validity and sensitivity has been reported (22-24). It is, therefore, of interest to know whether there is a relationship between measured feelings of depression or anxiety and the domains of the disease-specific CRQ (25).

A strong relationship would enable the CRQ to be used as a screening tool to help identify individuals most likely to experience feelings of anxiety and depression, who may then benefit from a more specific assessment. We aimed to determine whether the CRQ could be used as a screening tool for anxiety and depression. The purpose of the present study was to explore the relationships between common clinical outcomes measures (ie, HRQoL), which are routinely used in assessing the clinical status of patients with COPD, and the domains of depression and anxiety from the HADS score.

\section{METHODS}

\section{Study design}

The present analysis was a retrospective study. In August 2006, the authors' multidisciplinary clinical team incorporated the measurement of feelings of anxiety and depression using the HADS for patients with COPD enrolled in the inpatient PR program at West Park Healthcare Centre (Toronto, Ontario). The duration of the PR program is six weeks and includes the following components: supervised endurance exercise training five times per week; lower and upper extremity strength training three times per week; daily breathing exercises; self-management education; and psychological and social support. Following approval from the local research ethics board, baseline HADS scores, as well as baseline measures of functional exercise capacity and HRQoL, were retrieved from clinical records by trained professionals overseeing all patients admitted between August 2006 and August 2008. No other studies have been published using these data.

\section{Patients}

Patients enrolled in the PR program completed the HADS (administered by a nurse) in addition to routine outcome measures of HRQoL (self-administered) and the 6 min walk test, surpervised by a physical therapist. Patients eligible for review met the following criteria: physician-based diagnosis of COPD; clinically stable in the four weeks before the time of measurement (7); able to communicate in English; and absence of comorbid conditions likely to influence outcome measures (eg, patients with musculoskeletal dysfunction, ie, limitation during gait). No specific sample size was calculated. Records from all patients with HADS scores were analyzed over the study period.

\section{Outcomes}

The HADS is comprised of two subscales: one for feelings of depression and one for feelings of anxiety. It is a questionnaire with a total of 14 items and four categories for each. It can be used to categorize patients into three groups: no anxiety and/or depression (scores from 0 to 7); probable anxiety and/or depression (scores from 8 to 10); and presence of anxiety and/or depression (scores from 11 to 21) (18).

The CRQ is a 20-item questionnaire with standardized questions related to quality of life in four domains: dyspnea (CRQ-dys) - five items; fatigue (CRQ-fat) - four items; emotional function (CRQ-emo) - seven items; and mastery (CRQ-mas) - four items. For all items, patients rate their responses on a seven-point scale ranging from 1 (maximum impairment) to 7 (no impairment) (26).

The Medical Research Council (MRC) dyspnea scale provides information about the extent the breathlessness affecting mobility on a five-point scale (1 to 5), with higher scores indicating greater func- tional limitation (27). It reflects various degrees of functional limitation resulting from dyspnea.

The 6 min walk test is a measure of functional exercise capacity, with the primary outcome reported as walk distance (6MWD) (28). A minimum of two tests were conducted on admission to the PR program to account for improvement due to familiarization (29).

\section{Data analysis}

Descriptive characteristics, such as age, sex, height, weight and pulmonary function, were retrieved from the medical records. Continuous variables (subject's characteristics and 6MWD) were assessed to determine whether the assumptions for normal distribution were met. The HADS scores for anxiety and depression, the MRC and the CRQ were treated as ordinal variables (18).

Spearman's correlation coefficients were used to assess the relationship between HADS subscales and the CRQ, MRC and 6MWD. Correlation coefficients were interpreted as low $(\leq 0.39)$, moderate (0.40 to 0.79$)$ and high $(\geq 0.80)(30)$.

Categorical regression analysis was performed to verify the relationship of the HADS subscales with variables of CRQ, MRC and 6MWD. Categorical regression extends the standard regression approach by simultaneously scaling all variables. Scaling all variables at the numerical level corresponds to standard multiple regression analysis. The scaling variables reflect characteristics of the original variables and are treated as quantified categorical variables in the same way as numerical variables. Using nonlinear transformations, the variables are analyzed at all levels to find the best-fitting model (31). For the present analysis, based on their HADS scores, patients were classified as having no anxiety, probable anxiety or the presence of anxiety (anxiety subscale), and no depression, probable depression or the presence of depression (depression subscale). These groups were used as the dependent variables, and the four CRQ domains, MRC dyspnea and the 6MWD were the independent variables. Statistical significance was set at $\mathrm{P}<0.05$.

Additionally, categorical principal component analysis (PCA) was used. PCA is a data reduction technique that simultaneously quantifies categorical variables while reducing the dimensionality of the data. The optimal scaling approach allows the variables to be scaled at different levels and quantified in the specified dimensionality. The objective was to identify underlying principal components of a set of variables while maximizing the amount of variance accounted for by those variables (32). Data reduction is accomplished with minimal loss of clinical information because the principal components are ranked such that the first few components capture most of the variation present in the original data and subsequent components can be discarded. PCA has been used previously to analyze HADS scores (33). In the present study, the CRQ domains, MRC dyspnea and the 6MWD of each individual were included in the categorical PCA analysis.

To further understand data interpretation, the PCA biplot is a graphical display that illustrates the relationships among the components, original variables and observations $(34,35)$, with variables represented by vectors and observations, or the average score of all the individuals on each group, using symbols. The variables are standardized to remove any undue influence on the analysis. Standardizing the variables means that the vectors are scaled to have a unit length or maximum value of 1 in the original dimensional space and the origin of the vectors is equal to zero.

Interpretation of the PCA biplot involves observing the length, direction and position of the variables and observations. The length of each vector approximates the amount of variance, and the longer vectors indicate higher variance (36). The relative angle between any two variables' vectors represents their pairwise correlation; the closer the vectors are to one another $\left(<90^{\circ}\right)$, the higher their correlation. When vectors are perpendicular (angles approaching $90^{\circ}$ or $270^{\circ}$ ), the variables have a small or no correlation. Angles approaching $0^{\circ}$ or $180^{\circ}$ (collinear vectors) indicate a correlation of 1 or -1 , respectively (33). 
TABLE 1

\section{Patient characteristics}

\begin{tabular}{lc}
\hline Characteristic & Mean \pm SD \\
\hline Age, years & $69 \pm 10$ \\
Body mass index, $\mathrm{kg} / \mathrm{m}^{2}$ & $27 \pm 8$ \\
Forced expiratory volume in 1 s, \% predicted & $46 \pm 21$ \\
Forced vital capacity, \% predicted & $78 \pm 23$ \\
DL & 49 predicted \\
Functional residual capacity, \% predicted & $49 \pm 22$ \\
\hline
\end{tabular}

$D L_{\text {co }}$ Single breath diffusing capacity of the lung for carbon monoxide

The direction of the variables' vectors is toward the highest values of the variables. In addition, the direction of the vectors reflects the component to which each variable is most strongly related. Another characteristic that can be extracted from the PCA biplot is the spatial proximity of the groups in relation both to one another and to a set of variables. When the observations are close to one another and near a set of variables, it is a sign that the groups share similarities for that specific set of variables. Furthermore, the projection (perpendicular line from the observation to the variable vector) of the observations onto the variables' vectors reflects their approximate value. When the projection is in the direction of the variables, it means that the group has a higherthan-average value for that specific variable; when it is in the opposite direction of the vector, the value is lower than average. This method has been explained in detail elsewhere $(34,35,37)$. SPSS version 20 (IBM Corporation, USA) and MATLAB R2011a were used for the analysis.

\section{RESULTS}

HADS scores were available for 80 patients ( 36 men, 44 women). Data for all outcomes available in this group of 80 patients were analyzed.

Table 1 summarizes the characteristics of the patients in the study. With patients grouped according to their scores on the anxiety subscale, $43(54 \%)$ were classified as having no anxiety, 21 (26\%) were classified as having probable anxiety and $16(20 \%)$ were classified as having the presence of anxiety. With patients grouped according to their scores on the depression subscale, using the same threshold for group classification, 43 (54\%) were classified as no depression, 17 (21\%) as probable depression and $20(25 \%)$ as the presence of depression. Six patients $(7 \%)$ were classified as showing presence of anxiety and depression. Table 2 shows the characteristics of the patients according to MRC and 6MWD data, and CRQ and HADS subscales.

Associations between the scores for the anxiety and depression subscales (HADS) and the CRQ domains, MRC and 6MWD are shown in Table 3. A moderate relationship was demonstrated between the anxiety subscale of the HADS and both CRQ-emo $(r=-0.519$; $\mathrm{P}<0.01)$ and $C R Q$-mas $(r=-0.553 ; \mathrm{P}<0.01)$.

The categorical regression analysis showed that $53 \%$ of the variance of anxiety was explained by the model that included all the dependent variables. Table 4 summarizes the standardized regression coefficients for the transformed predictors for both anxiety and depression. The largest coefficient occurred for CRQ-mas with the anxiety subscale $(-0.725$; $\mathrm{P}=0.019$ ). To interpret the contribution of $C R Q$-mas to the dependent variable anxiety subscale of the HADS, the partial correlation coefficient, which removed the linear effects of other predictors from both the predictor variable of interest and the response, was obtained. CRQ-mas explained $40 \%$ of the total variation in anxiety. The categorical regression for patients grouped according to their scores on the depression subscale of the HADS showed that only $43 \%$ of the variance of depression was explained by the regression on the predictors. The largest coefficient was found for the CRQ-mas domain; however, it was not statistically significant $(\mathrm{P}=0.650)$. None of the coefficients for depression were significant. Therefore, no further analysis was conducted.

Categorical PCA resulted in two components, PC1 (45.0\%) and PC2 $(20.3 \%)$, totaling $65.3 \%$ of the data variance explained. In the present study, PC1 captured the domains of the CRQ. Figure 1 displays the PCA biplot for anxiety, with the $\mathrm{x}$-axis represented by PC1 and the
TABLE 2

Dyspnea, functional exercise capacity, health-related quality of life, and anxiety and depression in the study patients

\begin{tabular}{lc}
\hline Variable & Mean \pm SD (range) \\
\hline Medical Research Council dyspnea scale & $4 \pm 1(1-5)$ \\
6 min walk distance, $\mathrm{m}$ & $298 \pm 105(52-518)$ \\
Chronic Respiratory Disease Questionnaire & \\
Dyspnea & $3 \pm 1(1-6)$ \\
Fatigue & $3 \pm 1(1-7)$ \\
Emotional function & $3 \pm 1(2-7)$ \\
Mastery & $4 \pm 1(1-7)$ \\
Total & $15 \pm 4(7-23)$ \\
Hospital Anxiety and Depression Scale & \\
Anxiety subscale & $3^{*}(0-19)$ \\
Depression subscale & $5^{*}(0-16)$ \\
\hline${ }^{*}$ Mode &
\end{tabular}

TABLE 3

Spearman correlation coefficients between anxiety and depression subscale scores with clinical outcome measures

\begin{tabular}{llcl}
\hline HADS subscale & Outcome measure & $\mathbf{R}$ & $\mathbf{P}$ \\
\hline Anxiety & CRQ Dyspnea & -0.215 & 0.074 \\
& CRQ Fatigue & -0.366 & $0.002^{*}$ \\
& CRQ Emotional function & -0.519 & $0.001^{*}$ \\
& CRQ Mastery & -0.553 & $0.001^{*}$ \\
& MRC & 0.148 & 0.242 \\
Depression & 6 min walk distance & -0.235 & 0.037 \\
& CRQ Dyspnea & -0.047 & 0.701 \\
& CRQ Fatigue & -0.382 & $0.001^{*}$ \\
& CRQ Emotional function & -0.356 & $0.003^{*}$ \\
& CRQ Mastery & -0.263 & $0.029^{*}$ \\
& MRC & 0.167 & 0.189 \\
& 6 min walk distance & -0.189 & 0.095 \\
\hline
\end{tabular}

${ }^{*} P<0.05$. HADS Hospital Anxiety and Depression scale; CRQ Chronic Respiratory Disease Questionnaire; MRC Medical Research Council dyspnea scale

$\mathrm{y}$-axis by PC2. Maximum variance (reflected as the corresponding values on the $\mathrm{x}$-axis or $\mathrm{y}$-axis) was attributed to the variables CRQ-mas for $\mathrm{PC} 1$ and MRC for PC2. The CRQ domains contributed to the structure of PC1 (more 'parallel' with PC1 than PC2 axis) and the functional measures, MRC and 6MWD, contributed to the structure of PC2 (more 'parallel' with PC2 than PC1 axis). The variables MRC and 6MWD are opposite in behaviour and highly negatively correlated. On the other hand, the CRQ domains are highly positively correlated, principally CRQ-mas and CRQ-dys (ie, small angle between the vectors).

The average position of the groups in the PCA biplot is shown with a square, triangle and circle representing the groups with no anxiety, probable anxiety and presence of anxiety, respectively (Figure 1). The projection of the no anxiety group is on the highest values of the CRQ domains and is close to the vertices of the variables MRC and 6MWD. Therefore, the group without anxiety shows high values for the CRQ domains and average values for the functional measures. The projections of the groups with probable anxiety and presence of anxiety are on the lower values of the CRQ domains (or on the left side of the vertices) demonstrating that probability and presence of anxiety reflect lower HRQoL measures compared with those without anxiety.

In Figure 1, the dashed line for the CRQ-mas vector was extended (dashed line was omitted from other variables for clarity purposes) to demonstrate the projection of the groups with probable and presence of anxiety on the CRQ-mas domain. The highest distance between the projections of the groups is along the domain of CRQ-mas; therefore, CRQ-mas was important in separating the no anxiety group from the other two groups.

Figure 2 shows the PCA biplot for depression with a similar pattern as described for anxiety, except in relation to group separation. The 
TABLE 4

Standardized coefficients of the predictors for the conditions anxiety and depression

\begin{tabular}{|c|c|c|c|c|c|c|c|c|}
\hline \multirow[b]{2}{*}{ Variable } & \multicolumn{4}{|c|}{ Anxiety } & \multicolumn{4}{|c|}{ Depression } \\
\hline & B & $\mathrm{SE}$ & $\mathbf{F}$ & $\mathbf{P}$ & B & SE & $\mathbf{F}$ & $\mathbf{P}$ \\
\hline CRQ Dyspnea & 0.007 & 0.601 & 0.000 & 0.991 & 0.290 & 0.612 & 0.224 & 0.800 \\
\hline CRQ Fatigue & 0.730 & 0.818 & 0.796 & 0.622 & -0.446 & 0.743 & 0.361 & 0.871 \\
\hline CRQ Mastery & -0.725 & 0.417 & 3.022 & $0.019^{\star}$ & 0.487 & 0.650 & 0.561 & 0.729 \\
\hline MRC & -0.487 & 0.502 & 0.942 & 0.400 & 0.158 & 0.425 & 0.138 & 0.936 \\
\hline 6 min walk distance & 0.005 & 0.277 & 0.000 & 0.985 & -0.129 & 0.332 & 0.151 & 0.700 \\
\hline
\end{tabular}

*Statistically significant $(P<0.05)$. CRQ Chronic Respiratory Disease Questionnaire; MRC Medical Research Council dyspnea scale; SE Standard error

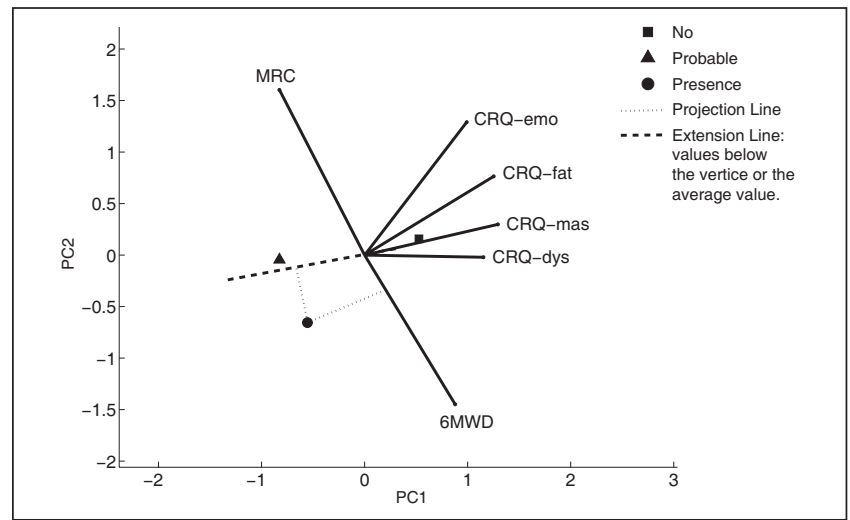

Figure 1) Principal component analysis biplot of the predictor variables and the average score of the groups for anxiety. The $x$-axis is represented by PC1 and the $y$-axis by PC2. The origin of the vectors indicates an average score for all variables. The vectors lines have a maximum length of 1 unit; the figure has been multiplied by a scale factor to enhance the image. A long solid line corresponds to a variable well represented in the dimensions. The angle between the vectors represents the correlation between the variables (ie, small angle implies a high correlation). The projection of each symbol on the vector line approximates the value of that variable for the symbol. All variables' vectors were scaled by a constant factor such that the distances between groups and the vector lengths are on the same scale. 6MWD 6 min walk distance; CRQ Chronic Respiratory Disease Questionnaire; CRQ-dys CRQ Dyspnea; CRQ-emo CRQ Emotional function; CRQ-fat CRQ Fatigue; CRQ-mas CRQ Mastery; MRC Medical Research Council dyspnea scale

interpretation of the biplot shows that none of the variables could separate the groups, or the distance between the projection of the groups along the domains were similar. None of the variables appeared to be more important for discriminating these groups. The regression analysis failed to demonstrate any variable importance, supporting this finding.

\section{DISCUSSION}

The main finding of the present study was that measures of HRQoL may be able to distinguish COPD patients who experience feelings of anxiety from those who do not. This finding will need to be confirmed prospectively. Specifically, a moderate yet significant correlation was observed between CRQ domains emotional function and mastery, and the anxiety subscale of the HADS, suggesting that patients with a low score in those domains (indicating worse health status) are more likely to experience symptoms of anxiety. On the other hand, taking into account that there was no significant relationship between HRQOL and the HADS depression subscale, it was not possible to distinguish patients with depression from those without depression using HRQoL measures.

The aim of the present study was to investigate the relationship between clinical measures regularly used in patients with COPD, enrolled in a PR, and measurements of depression and anxiety not commonly included as part of patient assessment. The present study was the first to apply PCA biplot to understand these relationships. The PCA biplot provided graphic approximation of the data sets and insight into

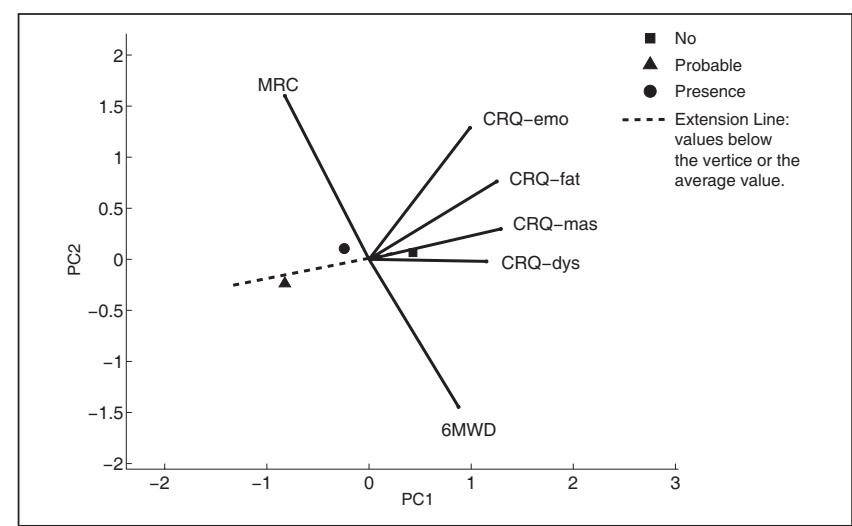

Figure 2) Principal component analysis biplot of the predictor variables and the average score of the groups for depression. 6MWD 6 min walk distance; CRQ Chronic Respiratory Disease Questionnaire; CRQ-dys CRQ Dyspnea; CRQ-emo CRQ Emotional; CRQ-fat CRQ Fatigue; CRQ-mas CRQ Mastery; MRC Medical Research Council dyspnea Scale. For details, see Figure 1 caption

relationships, trends and clusters among the variables and groups. This information extends what can be extracted by simple correlation.

Almost $40 \%$ of the symptoms of anxiety were accounted for by the CRQ-mas domain. It should be emphasized that this was the variable that best separated the no anxiety group from those with symptoms of anxiety, and is consistent with patients having a greater sense of mastery over their functioning also being less anxious. Individuals with low mastery scores may be especially targeted for more a formal assessment of anxiety.

There was no relationship between the CRQ and the HADS depression subscale, either by regression or by correlation analysis. This observation supports the report by Puhan et al (21), who did not identify any association between the CRQ and the depression subscale of the HADS in a sample of 88 patients with moderate to severe COPD. Therefore, clinicians cannot rely on the CRQ to identify patients who experience symptoms of depression (38). The PCA biplot findings further support the lack of association between the HADS depression subscale and HRQoL. Moreover, it can be hypothesized that the fact the studied population was involved in a PR may reflect a higher level of physical activity and lower presence of depression.

In individuals with COPD, it is possible that the presence of anxiety reflects anticipation of situations that may cause shortness of breath (38). On the other hand, depression may be related, at least in part, to a change of mood, irritability, disturbances in sleep and appetite (39). Therefore, it appears reasonable that CRQ-mas, which reflects the patients' confidence and control over the symptoms of the disease, may be more closely associated with an acute state, such as anxiety, than to depression.

Our results suggest a lack of a relationship between feelings of anxiety and depression and functional measures, a finding supported by Janssen et al (20). In contrast, Giardino et al (40) found that anxiety was associated with 6MWD in patients with moderate to severe emphysema. There is a need for further research to elucidate the relationship between anxiety and depression using functional measures. 
The present study had limitations, the first of which was the relatively small sample size. Moreover, the use of a convenience sample and missing data from the records must be also considered. All subjects were enrolled in PR, which may reflect a higher level of physical activity and lower presence of depression. Therefore, the results cannot be generalized to all patients with COPD. It was also not possible to evaluate the effect of sex and impact of comorbidities such as sleep apnea.

\section{CONCLUSION}

Our results showed that the CRQ-mas domain may identify symptoms of anxiety in patients with COPD. Although the relationship is insufficiently robust for this domain to be a surrogate measure, clinicians should consider more detailed assessment of anxiety in patients with COPD who show low CRQ-mas scores. The relationship is, nevertheless, valuable

\section{REFERENCES}

1. Rabe KF, Hurd S, Anzueto A, et al. Global strategy for the diagnosis, management, and prevention of chronic obstructive pulmonary disease: GOLD executive summary. Am J Respir Crit Care Med 2007; 176:532-55.

2. Global Strategy for the Diagnosis, Management and Prevention of COPD. <www.goldcopd.org/> (Accessed March 28, 2013).

3. Public Health Agency of Canada. Life and breath: Respiratory disease in Canada. <www.phac-aspc.gc.ca/publicat/2007/lbrdc-vsmrc/tobaccotabagisme-eng.php> 2007 (Accessed March 28, 2013).

4. Celli BR, MacNee W. Standards for the diagnosis and treatment of patients with COPD: A summary of the ATS/ERS position paper. Eur Respir J 2004;23:932-46.

5. Dowson CA, Kuijer RG, Mulder RT. Anxiety and self-management behaviour in chronic obstructive pulmonary disease: What has been learned? Chron Respir Dis 2004;1:213-20.

6. Hill K, Geist R, Goldstein RS, Lacasse Y. Anxiety and depression in end-stage COPD. Eur Respir J 2008;31:667-77.

7. Xu W, Collet JP, Shapiro S, et al. Independent effect of depression and anxiety on chronic obstructive pulmonary disease exacerbations and hospitalizations. Am J Respir Crit Care Med 2008;178:913-20.

8. Laurin C, Moullec G, Bacon SL, Lavoie KL. Impact of Anxiety and Depression on COPD Exacerbation Risk. Am J Respir Crit Care Med 2012;185:918-23.

9. Abrams TE, Vaughan-Sarrazin M, Van der Weg MW. Acute exacerbations of chronic obstructive pulmonary disease and the effect of existing psychiatric comorbidity on subsequent mortality. Psychosomatics 2011;52:441-9.

10. Lou P, Zhu Y, Chen P et al. Interaction of depressive and anxiety symptoms on the mortality of patients with COPD: A preliminary study. COPD 2014;11:444-50.

11. Emery CF, Schein RL, Hauck ER, MacIntyre NR. Psychological and cognitive outcomes of a randomized trial of exercise among patients with chronic obstructive pulmonary disease. Health Psychol 1998;17:232-40.

12. Withers NJ, Rudkin ST, White RJ. Anxiety and depression in severe chronic obstructive pulmonary disease: The effects of pulmonary rehabilitation. J Cardiopulm Rehabil 1999;19:362-5.

13. Pirraglia PA, Casserly B, Velasco R, Borgia ML, Nici L. Association of change in depression and anxiety symptoms with functional outcomes in pulmonary rehabilitation patients. J Psychosom Res 2011;71:45-9.

14. Harrison SL, Greening NJ, Willians JEA, Morgan MDL, Steiner MC, Singh SJ. Have we underestimated the efficacy of pulmonary rehabilitation in improving mood? Respir Med 2012;106:838-44.

15. Goldberg R, Hillberg R, Reinecker L, Goldstein R. Evaluation of patients with severe pulmonary disease before and after pulmonary rehabilitation. Disabil Rehabil 2004;26:641-8.

16. Rennard S, Thomashow B, Crapo J, et al. Introducing the COPD foundation guide for the diagnosis and management of COPD, recommendations of the COPD Foundation. COPD 2013;10:378-89.

17. Brooks D, Sottana R, Bell B, et al. Characterization of pulmonary rehabilitation programs in Canada in 2005. Can Respir J 2007;14:87-92.

18. Zigmond AS, Snaith RP. The hospital anxiety and depression scale. Acta Psychiatr Scand 1983;67:361-70.

19. Bjelland I, Dahl AA, Haug TT, Neckelmann D. The validity of the Hospital Anxiety and Depression Scale. An updated literature review. J Psychosom Res 2002;52:69-77.

20. Janssen DJ, Spruit MA, Leue C, et al. Symptoms of anxiety and depression in COPD patients entering pulmonary rehabilitation. Chron Respir Dis 2010;7:147-57. given the frequency with which the CRQ is used to assess patients with COPD. Considering that none of the CRQ domains were able to discriminate the three groups of depression (no depression, probable and presence), specific validated tools to symptoms of depression should be used. Future studies assessing a large number of patients could be helpful.

AUTHOR CONTRIBUTIONS: Study concept and design: DB, KH; Data acquisition, analysis or interpretation of data: MT, IA, LB, CD, ML, VFP, RK, DB; Drafting the manuscript, revising it critically and approval of the submitted version: VFP, RK, KH, RG, DB.

DISCLOSURES: The authors have no financial disclosures or conflicts of interest to declare.

21. Puhan MA, Frey M, Buchi S, Schunemann HJ. The minimal important difference of the hospital anxiety and depression scale in patients with chronic obstructive pulmonary disease. Health Qual Life Outcomes 2008;6:46.

22. Williams JE, Singh SJ, Sewell L, Guyatt GH, Morgan MD. Development of a self-reported Chronic Respiratory Questionnaire (CRQ-SR). Thorax 2001;56:954-9.

23. Williams JE, Singh SJ, Sewell L, Morgan MD. Health status measurement: Sensitivity of the self-reported Chronic Respiratory Questionnaire (CRQ-SR) in pulmonary rehabilitation. Thorax 2003;58:515-8.

24. Schunemann HJ, Puhan M, Goldstein R, Jaeschke R, Guyatt GH. Measurement properties and interpretability of the Chronic Respiratory Disease Questionnaire (CRQ). COPD 2005;2:81-9.

25. Engstrom CP, Persson LO, Larsson S, Sullivan M. Health-related quality of life in COPD: Why both disease-specific and generic measures should be used. Eur Respir J 2001;18:69-76.

26. Schunemann HJ, Griffith L, Jaeschke R, et al. A comparison of the original chronic respiratory questionnaire with a standardized version. Chest 2003;124:1421-9.

27. Bestall JC, Paul EA, Garrod R, Garnham R, Jones PW, Wedzicha JA. Usefulness of the Medical Research Council (MRC) dyspnoea scale as a measure of disability in patients with chronic obstructive pulmonary disease. Thorax 1999;54:581-6.

28. ATS statement: Guidelines for the six-minute walk test. Am J Respir Crit Care Med 2002;166:111-7.

29. Eiser N, Willsher D, Dore CJ. Reliability, repeatability and sensitivity to change of externally and self-paced walking tests in COPD patients. Respir Med 2003;97:407-14.

30. Shavelson RJ. Statistical Reasoning for Behavioural Sciences, 3rd edn. Boston: Allyn and Bacon, 1996.

31. Meulman JJ, Heiser WJ. IBM SPSS Categories. Chicago: SPSS Inc, 2010.

32. Kirkwood RN, Resende RA, Magalhaes CM, Gomes HA, Mingoti SA, Sampaio RF. Application of principal component analysis on gait kinematics in elderly women with knee osteoarthritis. Braz J Phys Ther 2011;15:52-8.

33. De WL, Molas M, Dejaeger E, et al. The use of a biplot in studying outcomes after stroke. Neurorehabil Neural Repair 2009;23:825-30.

34. Gabriel KR. Analysis of meteorological data by means of canonical decomposition nad biplots. J Appl Meteor 1972;11:1071-7.

35. Gabriel KR, Odoroff CL. Biplots in biomedical research. Stat Med 1990;9:469-85.

36. Kohler U, Luniak M. Data inspection using biplot. Stata J 2005;5:208-23

37. Gower J, Lubbe S, Le Roux N. Understanding Biplots. London: John Wiley \& Sons, Ltd, 2010

38. Livermore N, Sharpe L, McKenzie D. Panic attacks and panic disorder in chronic obstructive pulmonary disease: A cognitive behavioral perspective. Respir Med 2010;104:1246-53.

39. Belmaker RH, Agam G. Major depressive disorder. N Engl J Med 2008;358:55-68.

40. Giardino ND, Curtis JL, Andrei AC, et al. Anxiety is associated with diminished exercise performance and quality of life in severe emphysema: A cross-sectional study. Respir Res 2010;11:29. 


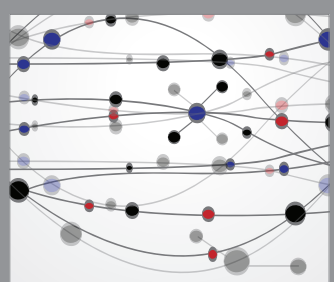

The Scientific World Journal
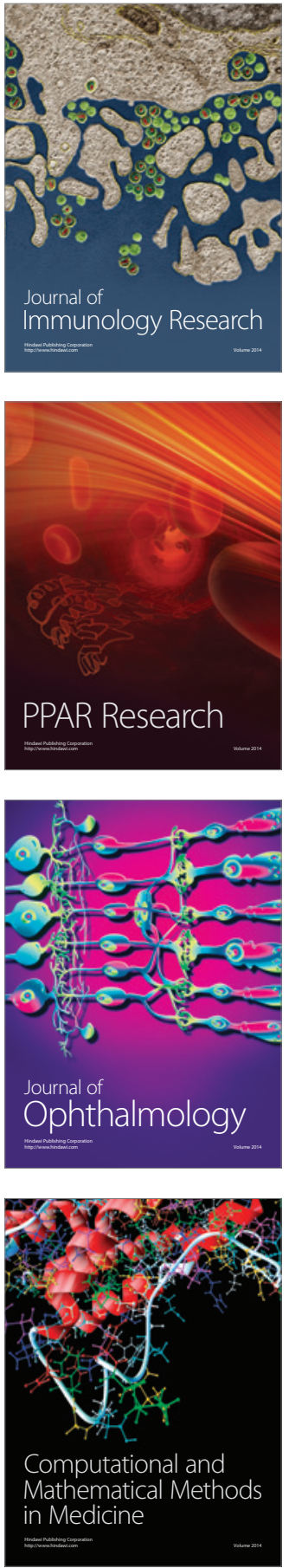

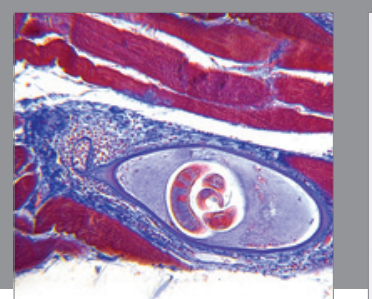

Gastroenterology Research and Practice

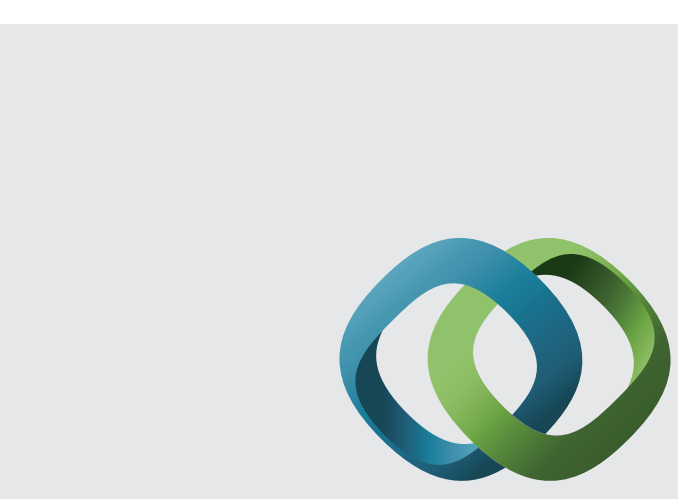

\section{Hindawi}

Submit your manuscripts at

http://www.hindawi.com
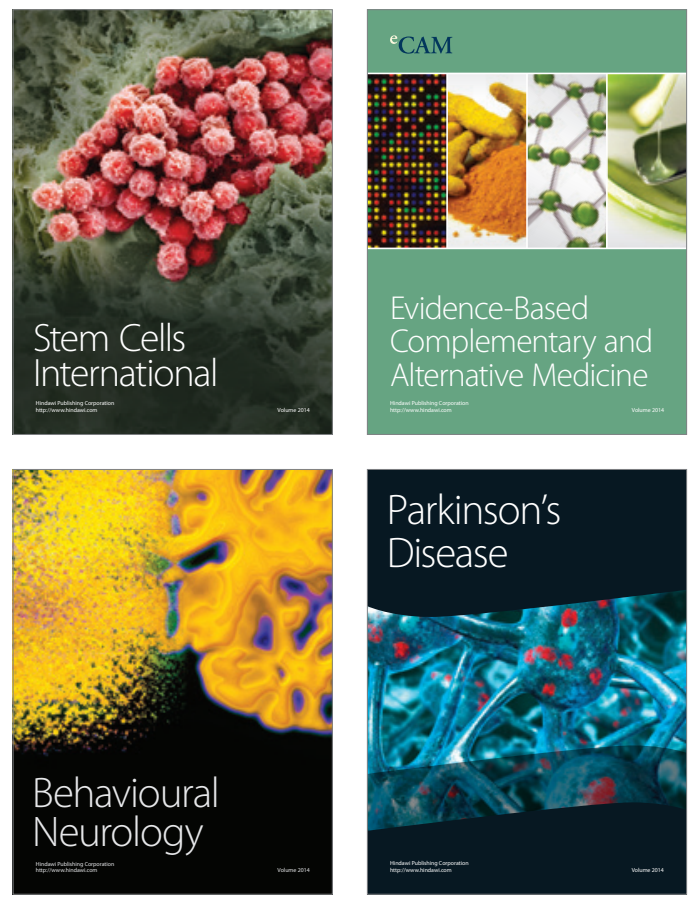
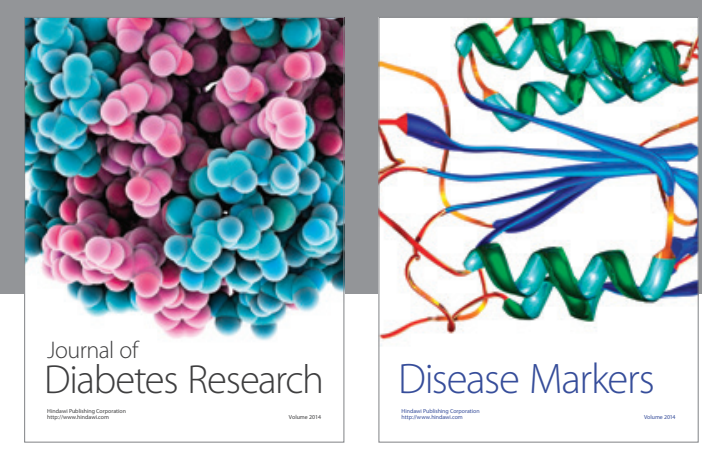

Disease Markers
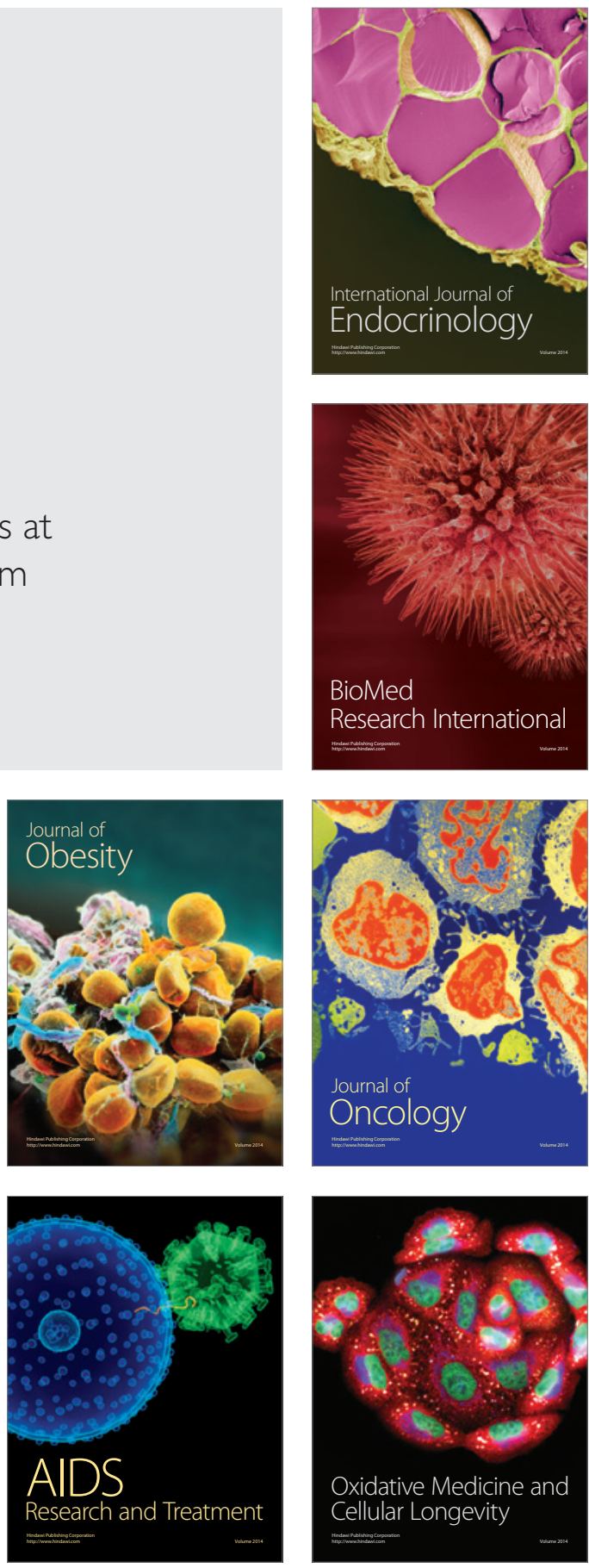